\title{
Evaluasi software aplikasi Senayan Library Management System (SLIMS) di lingkungan Universitas Lancang Kuning Pekanbaru menggunakan pendekatan ISO 9126 usability
}

\author{
Dwiyantoro \\ PT Chevron Pacific Indonesia, BP- E-Procurement System Team \\ Email: dwiyantoro66@gmail.com
}

\begin{abstract}
This research focuses on evaluating Senayan library management system (Slims) application software in the Lancang Kuning University environment using the ISO 9126.1 Usability approach. Research related to evaluation or application quality testing has been done a lot but for the evaluation of slims software in the Lancang Kuning University environment has never been done. In this research the method used is descriptive quantitative. With the method of collecting observation data, distributing questionnaires, and interviews. The sample in this study were 7 respondents from different libraries who used the slims application. Data analysis was performed using a Likert scale percentage formula. The results of this study indicate that based on the percentage of data using ISO 9126.1 usability on each attribute, namely Understandability with a percentage value of 116 predicate strongly agree, Learnability with a percentage value of 137 predicate agree, Opportunity with a value of 349 predicate strongly agree, Attactiveness with a value of 115 predicate strongly agree, and Usability Compliance with a rating of 115 is very much in agreement. From the results explained above, it can be concluded that Slims meet ISO 9126.1 usability standards.
\end{abstract}

Keyword: Software Slims; Library; ISO 9126.1 Usability; Lancang Kuning University.

\begin{abstract}
ABSTRAK
Penelitian ini berfokus pada evaluasi software aplikasi senayan library management system (Slims) d lingkungan Universitas Lancang Kuning Pekanbaru menggunakan pendekatan ISO 9126.1 Usability. Penelitian terkait evaluasi atau pengujian kualitas aplikasi sudah banyak dilakukan namun untuk evaluasi software slims di lingkungan Univeristas Lancang Kuning Pekanbaru belum pernah dilakukan. Dalam penelitian ini metode yang digunakan yaitu deskriptif kuantitatif. Dengan metode pengumpulan data observasi, penyebaran kuesioner, dan wawancara. Sampel dalam penelitian ini yaitu 7 responden yang berasal dari perpustakaan berbeda yang menggunakan aplikasi slims. Analisis data dilakukan dengan menggunakan rumus persentase skala likert. Hasil penelitian ini menunjukkan bahwa berdasarkan persentase data menggunakan ISO 9126.1 usability pada tiap atribut yaitu Understandability dengan nilai persentase 116 predikat sangat setuju, Learnability dengan nilai persentase 137 predikat setuju, Oportunity dengan nilai 349 predikat sangat setuju, Attactiveness dengan nilai 115 predikat sangat setuju, dan Usability Compliance dengan nilai 115 predikat sangat setuju. Dapat dari hasil yang dijelaskan tersebut maka dapat ditarik kesimpulan bahwa Slims sudah menenuhi standar ISO 9126.1 usability.
\end{abstract}

Kata Kunci: Software Slims; Perpustakaan; ISO 9126.1; Universitas Lancang Kuning

\section{A. PENDAHULAN}

Saat ini perkembangan teknologi bergerak begitu pesat tidak dapat di pungkiri bahwa setiap harinya manusia tidak lepas dari teknologi. Hal ini tentunya memberikan dampak yang baik karena teknologi saat ini menawarkan banyak sekali kemudahan seperti akses 
informasi, kemudahan dalam menyediakan transportasi, dan masih banyak lagi kemudahan yang ditawarkan oleh teknologi. salah satu dampak positif dari teknologi ini yaitu kemudahan mengelola informasi bagi instansi perpustakaan baik perpustakaan sekolah, perpustakaan perguruan tinggi, perpustakaan khusus, perpustakaan umum, ataupun taman bacaan masyarakat.

Sebagai salah satu sumber informasi yang dapat digunakan untuk mencari referensi bagi para peneliti, siswa, guru, dosen, dan masyarakat umum, tentunya diperlukan pengelolan yang sistematis, baik itu pengelolaan koleksi, pengelolaan angota, sirkulasi peminjaman, dan kemudahan yang ditawarkan agar dapat dengan mudah mencari informasi yang di butuhkan. Tentunya teknologi pada bidang perpustakaan ini sangat lah membantu jika fitur yang ditawarkan dalam satu sistem dapat mencakup pengelolaan perpustakaan. Salah satu teknologi yang menawarkan pengelolaan informasi bidang perpustakaan ini adalah senayan library management system (Slims).

Slims merupakan software yang di kembangkan oleh Pusat Informasi Dan Humas Departemen Pendidikan Nasional dan di ciptakan oleh Hendro Wicaksono pata tahun 2009. Berdasarkan ata statistik yang didapatkan pada laman (Slims 2019) dikatakan bahwa jumlah pengguna slims 1923 instansi di Indonesia data ini di update pada tanggal 15 April 2019. Salah satu instansi perpustakaan yang menggunakan slims. berdasarkan observasi yang dilakukan terdapat 9 perpustakaan yang berada di lingkungan Universitas lancang kuning yang menggunakan aplikasi ini.

Slims merupakan software open source yang dapat di unduh secara gratis, selain itu software ini dapat digunakan pada beberapa browser diantaranya yaitu google chrome, internet exsploler, dan media browser lainnya. Salah satu kemudahan yang ditawarkan oleh slims ini diantarannya yaitu, didukung dengan online public access catalog, manajemen record, sirkulasi, laporan dan statistik, dan fitur-fitur lainnya. Dari kemudahan-kemudahan yang di tawarkan software slims tersebut tentunya perlu dievaluasi baik dari segi penggunaan, efesiensi, keamanan, fungsi, serta kenadalan sistem. Hal ini dilakukan untuk melihat apakah slims sudah memenuhi standar ISO atau belum memenuhi standar.

Evaluasi dapat dilakukan dengan menggunakan ISO 9126.1 dimana ISO 9126 merupakan internasional standar yang digunakan untuk menganalisis kualitas software. Menurut (Abran and Al-qutaish 2018) mengatakan bahwa:

"ISO published its fi rst international consensus on the terminology for the quality characteristics for software product evaluation: ISO 9126 - Software Product Evaluation - Quality Characteristics and Guidelines for their"

Pendapat di atas menjelaskan bahwa ISO 9126 merupakan standar evaluasi produk perangkat lunak, karakteristik dan pedoman perangkat lunak untuk penggunannya. Analisis yang terdapat pada ISO(9126.1 2000) dikelompokan menjadi 6 poin diantaranya yaitu Functionality (Fungsionalitas), Reliability (Kehandalan), Usability (Ketergunaan), Efficiency (Efisiensi), Maintainability (Keterpeliharaan), Portability (Portabilitas).

Penelitain sebelumnya mengenai analisis kualitas software menggunakan ISO 9126 ini dilakukan oleh (Petrus 2018) dengan judul "ISO 9126 Untuk Pengujian Kualitas Aplikasi Perpustakaan Senayan Library Management System (SLIMS)", selain itu penelitain selanjutnya yang terkaita ISO 1926 dilakukan oleh (Melathi and Suharso 2017) Dengan Judul Penerapan Model Kualitas ISO/IEC 9126 Untuk Evaluasi Sistem Informasi Akademik Lembaga Bimbingan Belajar Berbasis Web". Selanjutnya penelitian yang dilakukan oleh (Abran et al. n.d.) dengan judul " ISO 9126: Analysis Of Quality Models And Measure”.

Berdasarkan uraian di atas mengenai slims perpustakaan yang berada dibawah instansi Universitas Lancang Kuning perlu dilakukan penelitian. Hal ini dilakukan untuk melihat kualitas software berdasarkan persepsi penggunanya. Dalam penelitian ini peneliti hanya 
berfokus pada poin Usability yang ada pada ISO 9126 dengan sub poin diantaranya yaitu Understandability, Learnability, Oportunity, Attactiveness, Usability Compliance.

Berdasarkan penjelasan di atas maka rumusan masalah dalam penelitian ini yaitu "Evaluasi Software Aplikasi Senayan Library Management System (SLIMS) di Lingkungan Universitas Lancang Kuning Pekanbaru Menggunakan Pendekatan ISO 9126 Usability”

\section{B. TINJAUAAN PUSTAKA}

\section{Sistem Informasi}

Sistem informasi merupakan kumpulan komponen yang saling terhubung, saling terkoneksi dapat menyimpan serta mengintegrasikan informasi guna mempermudah proses kerja dan pengambilan keputusan dalam sebuah organisasi. Menurut (Supriyatna 2015) sistem informasi adalah sistem yang saling terhubung, mengumpulkan dan mendapatka, serta menyimpan dan mendistribukikan informasi yang tersedia dalam sistem untuk dapat dipergunakan sebagai pengambilan keputusan dalam sebuah organisasi. Sedangkan menurut Rymond Mcleod dalam (Kriswanto et al. 2019)(Anggadini 2018) mengatakan bahwa suatu sistem berbasis komputer yang menyedikan berbagai informasi untuk berbagai pemakai dalam memenuhi kebutuhan.

Sedangkan untuk tujuan dari sistem informasi sendiri menurut O'Brien dan Marakas dalam (Anggadini 2018) mengatakan bahwa menyediakan informasi yang dipergunakan dalam perhitungan harga, jasa, produk dan tujuan lain sesuai dengan kebutuhan organisasi yang menggunakannya.

Berdasarkan pendapat di atas dapat dijelaskan bahwa, sistem informasi merupakan sekumpulan komponen yang saling terkoneksi, yang dapat menyimpan dan mendistribusikan informasi yang dibutuhkan oleh organisasi dan dapat dipergunakan untuk pengambilan keputusan organisasi yang menggunakannya.

\section{Software Aplikasi Slims}

Setiap organisasi memiliki sebuah sistem yang bertujuan untuk membantu proses pengerjaan, penyimpanan, dan penyebaran informasi dalam organisasi bersangkutan. Salah satu sistem informasi yang digunakan di dunia perpustakaan guna mempermudah proses pengelolaan informasi yaitu Senayan library management system atau disingkat dengan sebutan SLIMS. Slims merupakan sistem informasi yang dikembangan di Indonesia dan dapat di download secara gratis (open source). Salah satu pembuat slims adalah Hendro Wicaksono dan diproduksi oleh Pusat Informasi dan Humas Departemen Pendidikan Nasioanl. Menurut (Wicaksono 2010) menjelaskan bahwa Slims merupakan open source sortware (OOS) berbasis web untuk dapat memenuhi kebutuhan otomasi perpustakaan baik perpustakaan skala kecil ataupun skala besar. Selain itu pengiat slims dari spanyol mejelaskan bahwa:

"This is probably the best thing that can be. New features. The new look of the program, which is certainly ponrailsya smart people. So Matoa an embodiment of the future, and it has come now" berikut:

Adapun fitur-fitur yang dimiliki SLiMS diuraikan oleh (Wicaksono 2017) sebagai

a. Online Public Access Catalog (OPAC) fitur ini di buat agar penguna slim dapat dengan mudah melakukan penelususran informasi yang di butuhan dengan efektif dan efisien.

b. Instalasi. terdapat langkah-langkah mudah yang dapat dilkukan dalam proses instalasi ini, yang dapat digunakan untuk mempermudah pengguna dalam melakukan instalasi. 
c. Manajemen data bibliografi yang efisien meminimalisasi redundansi data.

d. Manajemen masterfile untuk data referensial seperti GMD (General Materia Sirkulasi dengan fitur: Designation), Tipe Koleksi, Penerbit, Pengarang, Lokasi, Supplier, dan lain-lain.

e. Sirkulasi dengan fitur:

1. Transaksi peminjaman dan pengembalian;

2. Reservasi koleksi;

3. Aturan peminjaman yang fleksibel;

4. Informasi keterlambatan dan denda.

5. Manajemen keanggotaan.

f. Inventarisasi koleksi (stock taking).

g. Laporan dan Statistik.

h. Pengelolaan terbitan berkala.

i. Dukungan pengelolaan dokumen multimedia (.flv,.mp3, dlsb.) serta dokumen dijital.

j. SLiMS mendukung beragam format bahasa termasuk bahasa yang tidak menggunakan penulisan selain latin.

k. Menyediakan berbagai bahasa pengantar (Indonesia, Inggris, Spanyol, Arab, Jerman, Bengali, Persia, Melayu, Portugis Brasil, Thailand, Jepang).

1. Dukungan Modul Union Catalog Service.

m. Penghitung Pengunjung perpustakaan.

n. Member Area untuk melihat koleksi sedang dipinjam oleh anggota.

o. Modul sistem dengan fitur:

1. Konfigurasi sistem global;

2. Manajemen modul;

3. Manajemen pengguna (grup pengguna dan pengguna aplikasi);

4. Pengaturan hari libur;

5. Pembuatan barcode otomatis;

6. Utilitas untuk backup.

\section{ISO 9126.1 Usability}

Internasional Organization For Standardization yang di singkat ISO. Adapun salah satu ISO yaitu ISO 9126 merupakan standar internasional yang digunakan untuk mengukur kualitas software. Menurut (Abran and Al-qutaish 2018) menjelaskan bahwa:

"ISO published its fi rst international consensus on the terminology for the quality characteristics for software product evaluation: ISO 9126 - Software Product Evaluation - Quality Characteristics and Guidelines for their Use".

Berdasarkan draf ISO (9126.1 2000) terdapat 6 poin penting yang terdapat dalam ISO 9126 diantaranya yaitu Functionality (Fungsionalitas), Reliability (Kehandalan), Usability (Ketergunaan), Efficiency (Efisiensi), Maintainability (Keterpeliharaan), Portability (Portabilitas).

Dalam penelitian ini fokus penelitian yaitu pada poin usability. Menurut (Abran et al. n.d.) menjelaskan bahwa definisi dari usabiliti adalah:

"The capability of the software product to be understood, learned, used and attractive to the user, when used under specified conditions."

Sedangkan dalam draf ISO dalam (Wahyuni 2014) dijelaskan bahwa poin usability merupakan suatu kemampuan perangkat lunak untuk dapat dipahami, dipelajari, digunakan dan menarik bagi pengguna, bila digunakan dalam kondisi tertentu. Selain itu menurut (Petrus 2018) Usability berkaitan dengan kualitas produk apakah produk tersebut dapat 
digunakan sesuai dengan tujuan dan dapat digunakan secara efektif dan efisien setelah digunakan.

Dari pendapat yang sudah di paparkan diatas maka dapat dijelaskan bahwa usability merupakan suatu kemampuan perangkat lunak untuk dapat dipahami, dipelajari dan digunakan serta menarik bagi pengunannya. Ada pun sub bagian usability menurut (Abran et al. n.d.) dibagi menjadi 5 yaitu Understandability, Learnability, Oportunity, Attactiveness, Usability Compliance. Berdasarkan draf ISO 9126 dalam (Wahyuni 2014) dijelaskan bahwa :

a. Understandability: kemampuan suatu perangkat lunak memungkinkan pengguna agar mampu memahami apakah perangkat lunak tersebut cocok dapat digunakan untuk tugas dan kondisi tertentu.

b. Learnability: kemampuan suatu perangkat lunak untuk mudah dipelajari oleh pengguna.

c. Operability: kemampuan suatu perangkat lunak supaya mudah dioperasikan dan dikendalikan oleh pengguna.

d. Attractiveness: kemampuan suatu perangkat lunak untuk dapat menarik pengguna.

e. Usability Compliance: kemampuan suatu perangkat lunak untuk mematuhi standar, konvensi yang berkaitan dengan kebergunaan (usability).

\section{METODE PENELITIAN}

Pada penelitian ini penulis menggunakan metode deskriptif kuantitatif, pengumpulan data dilakukan secara langsung kepada user pengguna aplikasi Slims pada perpustakaan yang berada pada lingkungan Universitas Lancang Kuning Pekanbaru.

Pengumpulan data dilakukan dengan dua cara yaitu Pertama data pimer, data ini didapatkan dengan cara melakukan penyebaran kuesioner kepada user yang menggunakan aplikasi slims, kedua data skunder, data ini didapatkan dari studi literatur yang berkaitan dengan sistem informasi perpustakaan dan berkaitan dengan ISO 9126.1.

Data primer didapatkan dari hasil kuesioner yang dilakukan kepada 9 responden khususnya pustakawan perpustakaan yang berada di Lingkungan Univeristas Lancang Kuning, ke 7 responden tersebut diantaranya yaitu perpustakaan fakultas ilmu budaya (FIB), perpustakaan fakultas ekonomi ( FE), perpustakaan fakultas hukum (FH), perpustakaan fakultas keguruan dan ilmu pendidikan (FKIP), perpustakaan fakultas kehutanan (FAHUTAN), perpustakaan pusat UNILAK. Responden mengisi kuesioner berdasarkan pada pengalaman yang didapatkan dari melakukan pengoprasian aplikasi Slims. Berikut kisi-kisi instrumen penelitian dapat dilihat pada tabel di bawah ini.

Tabel. 1. Kisi-kisi Instrumen Penelitian

\begin{tabular}{|c|l|l|c|}
\hline No. & \multicolumn{1}{|c|}{ Atribut Usability } & \multicolumn{1}{|c|}{ Nomor Pernyataan } & Jumlah \\
\hline 1 & Understandability & $1.1,1.2,1.3,1.4$ & 4 \\
\hline 2 & Learnability & $2.1,2.1,2.3,2.4,2.5$ & 5 \\
\hline \multirow{2}{*}{3} & Oportunity & $\begin{array}{l}3.1,3.2,3.3,3.4,3.5,3.6,3.7, \\
3\end{array}$ & 12 \\
\hline 4 & Attactiveness & $4.1,4.2,4.3,4.4$ & 4 \\
\hline 5 & Usability Compliance & $5.1,5.2,5.3,5.4$ & 4 \\
\hline \multicolumn{2}{|r|}{ Total } \\
\hline
\end{tabular}

Sumber data : Diolah tahun 2020

Variabel yang akan diteliti yaitu pengalaman responden dalam menggunakan slims terhadap pengujian variabel kualitas software menggunakan ISO 9126. Terdapat 6 poin penting dalam ISO 9126 diantaranya yaitu Functiona-lity, Reliability, Usability, Efficiency, Maintain-ability Portability. Namun dari ke 6 poin di atas peneliti hanya berfokus pada poin Usability . Adapun aspek Usability (kebergunaan) terbagi menjadi 5 poin diantaranya yaitu 
Understandability, Learnability, Operability, Attractiveness, Usability Compliance. Setelah didapatkan hasil dari kuesioner yang di sebarkan kepada respoden makan langkah selanjutnya yaitu melakukan analisi data. Analisi data dilakukan dengan cara tabulasi, kemudain untuk menganalisis poin dari ISO 9126 peneliti menggunakan rumus persentase yang dikemukakan (Arikunto 2005)sebagai berikut :

Keterangan:

$$
P=\frac{F}{N} X 100 \%
$$

$$
\begin{aligned}
& \mathrm{P}=\text { persentase } \\
& \mathrm{F}=\text { jumlah jawaban } \\
& \mathrm{n}=\text { jumlah pertanyaan }
\end{aligned}
$$

Untuk pembererian predikat dari dalam penelitian ini berdasarkan pernaataan dari (Arikunto and Suharsimi 2014) yaitu sebagai berikut :

$\begin{array}{cl}\text { Persentase } & \text { Predikat } \\ 81-100 \% & \text { Sangat Setuju } \\ 61-80 \% & \text { Setuju } \\ 41-60 \% & \text { Ragu-Ragu } \\ 21-40 \% & \text { Tidak Setuju } \\ 0-21 \% & \text { Sangat Tidak Setuju }\end{array}$

Selain dari data kuesioner peneliti juga melakukan wawancara terhadap responden terhadap aplikasi slims yang digunakan. Wawancara dilakukan khusus pada poin Usability ISO 9126.1.

\section{HASIL DAN PENELITIAN}

1. Gambaran Umum Senayan Library Management System (Slims).

Senayan library management system (Slims) merupakan aplikasi yang di kembangkan khusus untuk pengelolaan perpustakaan. Aplikasi ini di kembangakan oleh Pusat Informasi dan Departemen Humas Pendidikan Nasional dan dibuat oleh Hendro Wicaksono ditahun 2009. Saat ini Slims sudah mengalami beberapa kali update software, yang terbaru yaitu Slims 8.3.1 Akasia yang di update tahun 2018.

Adapun tampilan halaman utama pada slims 8.3.1 Akasia dapat dilihat pada gambar di bawah ini:

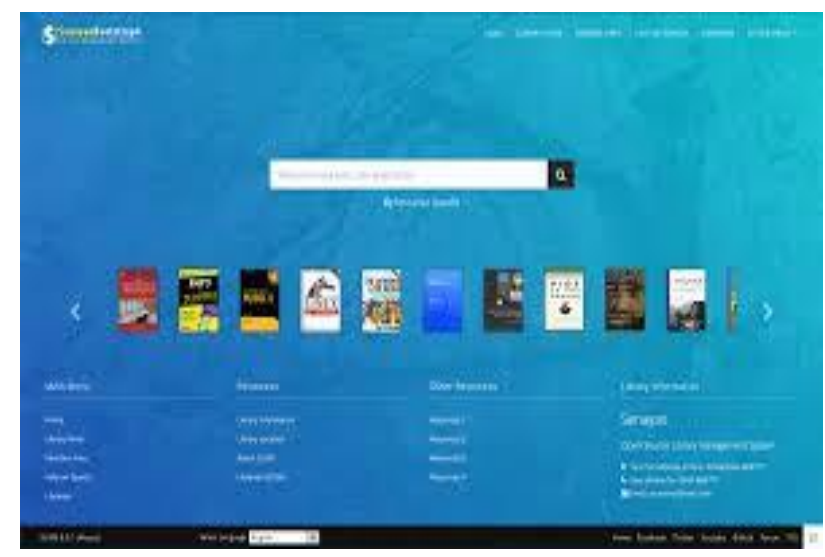

Gambar.1. Menu Utama Slims 8.3.1 Akasia 
Berdasarkan gambar di atas maka dapat dijelaskan bahwa untuk slims terbaru ini tampilan depan lebih menarik dan di bagian depan terdapat beberapa cover buku yang dapat kita tampilkan.

Berdasarkan hasil wawancara yang dilakukan dengan salah satu narasumber pengguna slims yaitu Bapak Eko Saputra pada tanggal 20 Januari 2020 Pukul 13.30 Wib, Berkaitan dengan tampilan dan item menu yang di tawarkan pada slims ini, belia menuturkan bahwa tampilan menu utama pada slims ini lebih mearik dan lebih mudah untuk digunakan sehingga saya pun lebih gampang untuk mengoprasikan aplikasi slims ini”.

Sedangkan untuk item-item lainnya yang tersedia seperi menejemen data, manajemen record, sirkulasi, inventarisasi, dan fitur-fitur lainnya mudah digunakan dan dipahami oleh penggunannya, hal ini dikemukakan oleh narasumber Eko Saputra dan Ibu Rosinta mengenai item dan fitur-fitur slims mengatakan bahwa " fitur yang ada pada slims mudah di pahami dan digunakan, sejauh ini slims memberikan dampak yang baik terhadap pengelolaan perpustakaan kami."

Dari penjelasan di atas makan dapat dijelaskan bahwa dari semua fitur-fitur yang di tawarkan slims memudahkan penggunannya dan mudah untuk di pahami penggunaannya.

2. Pengujian Kualitas Slims Menggunakan Pendekata ISO 9126.1 Usabilily di Perpustakaan Lingkungan Universitas Lancang Kuning

a. Hasil Adalisis Data Semua Atribut Usability ISO 9126.1

Berdasarkan hasil analisis yang dilakukan dari data yang diperoleh dari 7 responden dapat diketahui bahwa jumlah rata-rata nilai persetase pada setiap poin yang terdapat dalam usability ISO 9126.1 dapat dilihat pada keterangan di bawah ini:

\begin{tabular}{clc} 
Predikat & \multicolumn{1}{c}{ Keterangan } \\
Sangat Setuju & 7 Responden X 5 X 29 Butir Pertanyaan $=$ & $813-1.015$ \\
Setuju & 7 Responden X 4 X 29 Butir Pertanyaan $=$ & $610-812$ \\
Ragu-Ragu & 7 Responden X 3 X 29 Butir Pertanyaan $=$ & $407-609$ \\
Tisak Setuju & 7 Responden X 2 X 29 Butir Pertanyaan $=$ & $204-406$ \\
Sangat Tidak Setuju & 7 Responden X 1 X 29 Butir Pertanyaan $=$ & $0-203$
\end{tabular}

Berdasarkan keterangan di atas maka dapat dijelaskana bahwa keseluruhan hasil analisis data semua atribut usability dengan predikat sangat setuju dengan nilai 813-1015, predikat setuju dengan nilai 610-812, predikat ragu-ragu dengan nilai 407-609, predikat tidak setuju dengan nilai 204-406, dan predikat sangat tidak setuju dengan nilai 0-203.

\section{b. Hasil Analisis Data Atribut Understandability}

Berdasarkan hasil analisis data yang dilakukan terhadap 7 responden pengguna aplikasi slims yang berada di lingkungan Universitas Lancang Kuning. Di dapatkan hasil predikat pada atribut understandability dapat dijelaskan pada tabel di bawah ini:

\footnotetext{
Predikat

Sangat Setuju Setuju

Ragu-Ragu

Tisak Setuju

Keterangan

7 Responden X 5 X 4 Butir Pertanyaan $=113-140$

7 Responden X 4 X 4 Butir Pertanyaan $=85-112$

7 Responden X 3 X 4 Butir Pertanyaan $=57-84$

7 Responden X 2 X 4 Butir Pertanyaan $=29-56$

Sangat Tidak Setuju

7 Responden X 1 X 4 Butir Pertanyaan $=0-28$
} 
Tabel.2.Hasil Analisis data Atribut Understandability

\begin{tabular}{|l|l|c|c|c|c|c|}
\hline No & \multicolumn{1}{|c|}{ Responden } & $\mathbf{1 . 1}$ & $\mathbf{1 . 2}$ & $\mathbf{1 . 3}$ & $\mathbf{1 . 4}$ & jumlah \\
\hline 1 & Perpustakaan Pusat & 4 & 4 & 4 & 4 & $\mathbf{1 6}$ \\
\hline 2 & Perpustakaan FIB & 4 & 4 & 4 & 4 & $\mathbf{1 6}$ \\
\hline 3 & Perpustakaan FE & 4 & 4 & 4 & 4 & $\mathbf{1 6}$ \\
\hline 4 & Perpustakaan FP & 5 & 4 & 4 & 4 & $\mathbf{1 7}$ \\
\hline 5 & Perpustakaan FAHUTAN & 5 & 5 & 5 & 5 & $\mathbf{2 0}$ \\
\hline 6 & Perpustakaan FKIP & 4 & 4 & 3 & 4 & $\mathbf{1 5}$ \\
\hline 7 & Perpustakaan FH & 4 & 4 & 4 & 4 & $\mathbf{1 6}$ \\
\hline & Total & $\mathbf{3 0}$ & $\mathbf{2 9}$ & $\mathbf{2 8}$ & $\mathbf{2 9}$ & $\mathbf{1 1 6}$ \\
\hline
\end{tabular}

Sumber data : Diolah tahun 2020

Berdasarkan tabel di atas dapat dijelaskan bahwa dari ke empat pertanyaan yang di jawab oleh 7 responden menunjukkan hasil yang berbeda-beda. Untuk nilai tertinggi yaitu perpustakaan Fahutan dengan jumlah 20 sedangkan hasil yang didapatkan paling sedikit yaitu perpustakaan Fkip dengan jumlah 15. Total keseluruhan jawaban mengenai Understandability dari ke 7 responden yaitu 116 dengan predikat Sangat Setuju. Hal tersebut menunjukkan responden sangat setuju bahwa Slims memungkinkan pengguna agar mampu memahami apakah perangkat lunak tersebut cocok dapat digunakan untuk tugas dan kondisi tertentu.

\section{c. Hasil Analisis Data Atribut Learnability}

Berdasarkan hasil analisis data yang dilakukan terhadap 7 responden pengguna aplikasi slims yang berada di lingkungan Universitas Lancang Kuning. Di dapatkan hasil predikat pada atribut Learnability dapat dijelaskan pada tabel di bawah ini:

$\begin{array}{clc}\text { Predikat } & \text { Keterangan } \\ \text { Sangat Setuju } & 7 \text { Responden X 5 X 5 Butir Pertanyaan }= & 141-175 \\ \text { Setuju } & \text { 7 Responden X 4 X 5 Butir Pertanyaan }= & 105-140 \\ \text { Ragu-Ragu } & \text { 7 Responden X 3 X 5 Butir Pertanyaan }= & 71-105 \\ \text { Tisak Setuju } & \text { 7 Responden X 2 X 5 Butir Pertanyaan }= & 36-70 \\ \text { Sangat Tidak Setuju } & \text { 7 Responden X 1 X 5 Butir Pertanyaan }= & 0-35\end{array}$

Tabel.3.Hasil Analisis data Atribut Learnability

\begin{tabular}{|l|l|c|c|c|c|c|c|}
\hline No & \multicolumn{1}{|c|}{ Responden } & $\mathbf{2 . 1}$ & $\mathbf{2 . 2}$ & $\mathbf{2 . 3}$ & $\mathbf{2 . 4}$ & $\mathbf{2 . 5}$ & Jumlah \\
\hline 1 & Perpustakaan Pusat & 4 & 4 & 4 & 4 & 4 & $\mathbf{2 0}$ \\
\hline 2 & Perpustakaan FIB & 4 & 4 & 5 & 4 & 4 & $\mathbf{2 1}$ \\
\hline 3 & Perpustakaan FE & 4 & 3 & 3 & 3 & 3 & $\mathbf{1 6}$ \\
\hline 4 & Perpustakaan FP & 5 & 4 & 4 & 4 & 3 & $\mathbf{2 0}$ \\
\hline 5 & Perpustakaan FAHUTAN & 5 & 5 & 4 & 4 & 3 & $\mathbf{2 1}$ \\
\hline 6 & Perpustakaan FKIP & 4 & 4 & 4 & 4 & 3 & $\mathbf{1 9}$ \\
\hline 7 & Perpustakaan FH & 4 & 4 & 4 & 4 & 4 & $\mathbf{2 0}$ \\
\hline & Total & $\mathbf{3 0}$ & $\mathbf{2 8}$ & $\mathbf{2 8}$ & $\mathbf{2 7}$ & $\mathbf{2 4}$ & $\mathbf{1 3 7}$ \\
\hline
\end{tabular}

Sumber data : Diolah tahun 2020

Berdasarkan tabel di atas dapat dijelaskan bahwa dari ke lima pertanyaan yang di jawab oleh 7 responden menunjukkan hasil yang berbeda-beda. Untuk nilai tertinggi yaitu perpustakaan Fahutan dan perpustakaan FIB dengan jumlah 21 sedangkan hasil yang didapatkan paling sedikit yaitu perpustakaan FE dengan jumlah 16. Total keseluruhan jawaban mengenai Learnability dari ke 7 responden yaitu 137 dengan predikat Setuju. Hal tersebut menunjukkan responden setuju bahwa Slims memiliki kemampuan untuk mudah dipelajari oleh pengguna. 


\section{d. Hasil Analisis Data Atribut Oportunity}

Berdasarkan hasil analisis data yang dilakukan terhadap 7 responden pengguna aplikasi slims yang berada di lingkungan Universitas Lancang Kuning. Di dapatkan hasil predikat pada atribut Oportunity dapat dijelaskan pada tabel di bawah ini:

Predikat
Sangat Setuju
Setuju
Ragu-Ragu
Tisak Setuju
Sangat Tidak Setuju

$\begin{aligned} & \text { Keterangan } \\ & 7 \text { Responden X 5 X 12 Butir Pertanyaan }=337-420 \\ & 7 \text { Responden X 4 X 12 Butir Pertanyaan }=253-336 \\ & 7 \text { Responden X 3 X 12 Butir Pertanyaan }=169-252 \\ & 7 \text { Responden X 2 X 12 Butir Pertanyaan }=85-168 \\ & 7 \text { Responden X 1 X 12 Butir Pertanyaan }=0-84\end{aligned}$

Tabel.4.Hasil Analisis data Atribut Oportunity

\begin{tabular}{|l|l|c|c|c|c|c|c|c|c|c|c|c|c|c|}
\hline No & \multicolumn{1}{|c|}{ Responden } & $\mathbf{3 . 1}$ & $\mathbf{3 . 2}$ & $\mathbf{3 . 3}$ & $\mathbf{3 . 4}$ & $\mathbf{3 . 5}$ & $\mathbf{3 . 6}$ & $\mathbf{3 . 7}$ & $\mathbf{3 . 8}$ & $\mathbf{3 . 9}$ & $\mathbf{3 . 1 0}$ & $\mathbf{3 . 1 1}$ & $\mathbf{3 . 1 2}$ & jml \\
\hline 1 & Perpustakaan Pusat & 4 & 4 & 4 & 4 & 4 & 4 & 4 & 4 & 4 & 4 & 4 & 4 & $\mathbf{4 8}$ \\
\hline 2 & Perpustakaan FIB & 4 & 4 & 4 & 4 & 4 & 4 & 4 & 4 & 4 & 4 & 4 & 4 & $\mathbf{4 8}$ \\
\hline 3 & Perpustakaan FE & 4 & 4 & 3 & 3 & 4 & 4 & 3 & 3 & 4 & 4 & 4 & 2 & $\mathbf{4 2}$ \\
\hline 4 & Perpustakaan FP & 5 & 5 & 4 & 4 & 4 & 4 & 4 & 5 & 5 & 5 & 4 & 4 & $\mathbf{5 3}$ \\
\hline 5 & Perpustakaan FAHUTAN & 5 & 5 & 5 & 5 & 5 & 4 & 4 & 5 & 5 & 5 & 4 & 4 & $\mathbf{5 6}$ \\
\hline 6 & Perpustakaan FKIP & 4 & 4 & 3 & 4 & 4 & 4 & 4 & 4 & 3 & 4 & 4 & 5 & $\mathbf{4 7}$ \\
\hline 7 & Perpustakaan FH & 5 & 5 & 5 & 5 & 4 & 4 & 4 & 4 & 4 & 5 & 5 & 5 & $\mathbf{5 5}$ \\
\hline & Total & $\mathbf{3 1}$ & $\mathbf{2 8}$ & $\mathbf{2 9}$ & $\mathbf{2 9}$ & $\mathbf{2 8}$ & $\mathbf{2 7}$ & $\mathbf{2 9}$ & $\mathbf{2 9}$ & $\mathbf{3 1}$ & $\mathbf{2 9}$ & $\mathbf{2 8}$ & $\mathbf{3 4 9}$ \\
\hline
\end{tabular}

Berdasarkan tabel di atas dapat dijelaskan bahwa dari ke dua belas pertanyaan yang di jawab oleh 7 responden menunjukkan hasil yang berbeda-beda. Untuk nilai tertinggi yaitu perpustakaan FH dengan jumlah 55 sedangkan hasil yang didapatkan paling sedikit yaitu perpustakaan FE dengan jumlah 42. Total keseluruhan jawaban mengenai Oportunity dari ke 7 responden yaitu 349 dengan predikat Sangat Setuju. Hal ini menunjukkan responden sangat setuju bahwa slims memiliki kemampuan kemudah untuk dioperasikan dan dikendalikan oleh pengguna.

\section{e. Hasil Analisis Data Atribut Attactiveness}

Berdasarkan hasil analisis data yang dilakukan terhadap 7 responden pengguna aplikasi slims yang berada di lingkungan Universitas Lancang Kuning. Di dapatkan hasil predikat pada atribut Attactiveness dapat dijelaskan pada tabel di bawah ini:

\footnotetext{
Predikat

Sangat Setuju

Setuju

Ragu-Ragu

Tisak Setuju

Keterangan

7 Responden X 5 X 4 Butir Pertanyaan $=113-140$

7 Responden X 4 X 4 Butir Pertanyaan $=85-112$

7 Responden X 3 X 4 Butir Pertanyaan $=57-84$

7 Responden X 2 X 4 Butir Pertanyaan $=29-56$

Sangat Tidak Setuju 7 Responden X 1 X 4 Butir Pertanyaan $=0-28$
}

Tabel.5.Hasil Analisis data Atribut Attactiveness

\begin{tabular}{|l|l|c|c|c|c|c|}
\hline No & Responden & $\mathbf{4 . 1}$ & $\mathbf{4 . 2}$ & $\mathbf{4 . 3}$ & $\mathbf{4 . 4}$ & Jumlah \\
\hline 1 & Perpustakaan Pusat & 4 & 4 & 4 & 4 & $\mathbf{1 6}$ \\
\hline 2 & Perpustakaan FIB & 4 & 4 & 4 & 4 & $\mathbf{1 6}$ \\
\hline 3 & Perpustakaan FE & 3 & 4 & 4 & 4 & $\mathbf{1 5}$ \\
\hline 4 & Perpustakaan FP & 4 & 5 & 5 & 4 & $\mathbf{1 8}$ \\
\hline 5 & Perpustakaan FAHUTAN & 4 & 5 & 5 & 4 & $\mathbf{1 8}$ \\
\hline 6 & Perpustakaan FKIP & 3 & 3 & 3 & 3 & $\mathbf{1 2}$ \\
\hline 7 & Perpustakaan FH & 5 & 5 & 5 & 5 & $\mathbf{2 0}$ \\
\hline & Total & $\mathbf{2 7}$ & $\mathbf{3 0}$ & $\mathbf{3 0}$ & $\mathbf{2 8}$ & $\mathbf{1 1 5}$ \\
\hline
\end{tabular}

Sumber Data : Diolah tahun 2020 
Berdasarkan tabel di atas dapat dijelaskan bahwa dari ke empat pertanyaan yang di jawab oleh 7 responden menunjukkan hasil yang berbeda-beda. Untuk nilai tertinggi yaitu perpustakaan $\mathrm{FH}$ dengan jumlah 20 sedangkan hasil yang didapatkan paling sedikit yaitu perpustakaan Fkip dengan jumlah 12 Total keseluruhan jawaban mengenai Attactivenes dari ke 7 responden yaitu 115 dengan predikat Sangat Setuju. Hal ini menunjukkan responden sangat setuju bahwa slims memiliki kemampuan untuk dapat menarik pengguna.

\section{f. Hasil Analisis Data Atribut Usability Compliance}

Berdasarkan hasil analisis data yang dilakukan terhadap 7 responden pengguna aplikasi slims yang berada di lingkungan Universitas Lancang Kuning. Di dapatkan hasil predikat pada atribut Usability compliance dapat dijelaskan pada tabel di bawah ini:

Predikat
Sangat Setuju
Setuju
Ragu-Ragu
Tisak Setuju
Sangat Tidak Setuju

$\begin{aligned} & \text { Keterangan } \\ & 7 \text { Responden X 5 X 4 Butir Pertanyaan }=113-140 \\ & 7 \text { Responden X 4 X 4 Butir Pertanyaan }=85-112 \\ & 7 \text { Responden X 3 X 4 Butir Pertanyaan }=57-84 \\ & 7 \text { Responden X 2 X 4 Butir Pertanyaan }=29-56 \\ & 7 \text { Responden X 1 X 4 Butir Pertanyaan }=0-28\end{aligned}$

Tabel.6.Hasil Analisis data Atribut Usability Compliance

\begin{tabular}{|l|l|c|c|c|c|c|}
\hline No & \multicolumn{1}{|c|}{ Responden } & $\mathbf{5 . 1}$ & $\mathbf{5 . 2}$ & $\mathbf{5 . 3}$ & $\mathbf{5 . 4}$ & Jumlah \\
\hline 1 & Perpustakaan Pusat & 4 & 4 & 4 & 4 & $\mathbf{1 6}$ \\
\hline 2 & Perpustakaan FIB & 4 & 4 & 4 & 4 & $\mathbf{1 6}$ \\
\hline 3 & Perpustakaan FE & 4 & 4 & 4 & 4 & $\mathbf{1 6}$ \\
\hline 4 & Perpustakaan FP & 4 & 4 & 5 & 4 & $\mathbf{1 7}$ \\
\hline 5 & Perpustakaan FAHUTAN & 5 & 5 & 5 & 3 & $\mathbf{1 8}$ \\
\hline 6 & Perpustakaan FKIP & 3 & 3 & 3 & 3 & $\mathbf{1 2}$ \\
\hline 7 & Perpustakaan FH & 5 & 5 & 5 & 5 & $\mathbf{2 0}$ \\
\hline & Total & $\mathbf{2 9}$ & $\mathbf{2 9}$ & $\mathbf{3 0}$ & $\mathbf{2 7}$ & $\mathbf{1 1 5}$ \\
\hline
\end{tabular}

Sumber Data : Diolah tahun 2020

Berdasarkan tabel di atas dapat dijelaskan bahwa dari ke empat pertanyaan yang di jawab oleh 7 responden menunjukkan hasil yang berbeda-beda. Untuk nilai tertinggi yaitu perpustakaan $\mathrm{FH}$ dengan jumlah 20 sedangkan hasil yang didapatkan paling sedikit yaitu perpustakaan Fkip dengan jumlah 12. Total keseluruhan jawaban mengenai Usability compliance dari ke 7 responden yaitu 115 dengan predikat Sangat Setuju. Hal ini menunjukkan responden sangat setuju bahwa Slims memiliki kemampuan untuk mematuhi standar, konvensi yang berkaitan dengan kebergunaan (usability).

\section{E. KESIMPULAN}

Berdasarkan hasil evaluasi yang dilakukan mengenai software aplikasi slims di lingkunan universitas lancang kuning pekanbaru menggunakan pendekatan ISO 9126.1 usability dapat disimpulkan nilai persentase data yang dilakukan menggunakan pendekatan ISO 9126.1 usability pada tiap atribut yaitu Understandability dengan nilai persentase 116 predikat sangat setuju, Learnability dengan nilai persentase 137 predikat setuju, Oportunity dengan nilai 349 predikat sangat setuju, Attactiveness dengan nilai 115 predikat sangat setuju, dan Usability Compliance dengan nilai 115 predikat sangat setuju. Dapat dari hasil yang dijelaskan tersebut maka dapat ditarik kesimpulan bahwa Slims sudah menenuhi standar ISO 9126.1 usability. Diharapkan kepada para peneliti selanjutnya untuk dapat memperdalam penelitian ini menggenai software aplikasi slims agar kedepannya aplikasi slims ini diharapkan lebih baik lagi dalam membantu para pustakawan dalam mengelola perpustakaan. 


\section{DAFTAR PUSTAKA}

9126.1, Draf ISO/IEC FDIS. 2000. "DRAFT INTERNATIONAL STANDARD ISO / IEC FDIS 9126-1."

Abran, Alain, and Rafa E Al-qutaish. 2018. ISO 9126: Analysis of Quality Models and Measures.

Abran, Alain, Adel Khelifi, Witold Suryn, and Ahmed Seffah. "Consolidating the ISO Usability Models." : 1-17.

Anggadini, Sri Dewi. 2018. "ANALISIS SISTEM INFORMASI MANAJEMEN BERBASIS KOMPUTER DALAM PROSES PENGAMBILAN KEPUTUSAN.” Majalah Ilmiah Unikom 11(2): 176-87.

Arikunto, Suharsimi. 2005. Manajemen Penelitian. Jakarta: Rineka Cipta.

Arikunto, and Suharsimi. 2014. Prosedur Penelitian: Suatu Pendekatan Praktik. Jakarta: Renika Cipta.

Kriswanto, Y Rudi et al. 2019. "Kecenderungan Topik Penelitian Di Bidang Ilmu Perpustakaan Dan Informasi Dengan Pendekatan Kaidah Zipf.” 15(1).

Melathi, Afininda Arum, and Wiwik Suharso. 2017. "Penerapan Model Kualitas ISO / IEC 9126 Untuk Evaluasi Sistem Informasi Akademik Lembaga Bimbingan Belajar Berbasis Web." Jurnal Sistem \& Teknologi Informasi Indonesia 2(1): 75-83.

Petrus, Dwi Ananto Pamungkas. 2018. "ISO 9126 Untuk Pengujian Kualitas Aplikasi Perpustakaan Senayan.” 2(2): 465-71.

Slims. 2019. "Daftra Pengguna Slims." https://slims.web.id/web/news/daftar-penggunaslims/. https://slims.web.id/web/news/daftar-pengguna-slims/.

Supriyatna, Adi. 2015. "Analisis Dan Evaluasi Kepuasan Pengguna Sistem Informasi Perpustakaan Dengan Menggunakan Pieces Framework." Jurnal Pilar Mandiri ANALISIS D(No 1): 43-52.

Wahyuni, Irma. 2014. "Evaluasi Sistem Automasi Perpustakaan SLiMS ( Senayan Library Management System ) Pada Perpustakaan Universitas Muhammadiyah Sumatera Utara."

Wicaksono, Hendro. 2010. "Manual Senayan Versi 4 Berdasar Senayan3-Stable14". 2010." —. 2017. Panduan Penggunaan Senayan Library Management System (Slims). 